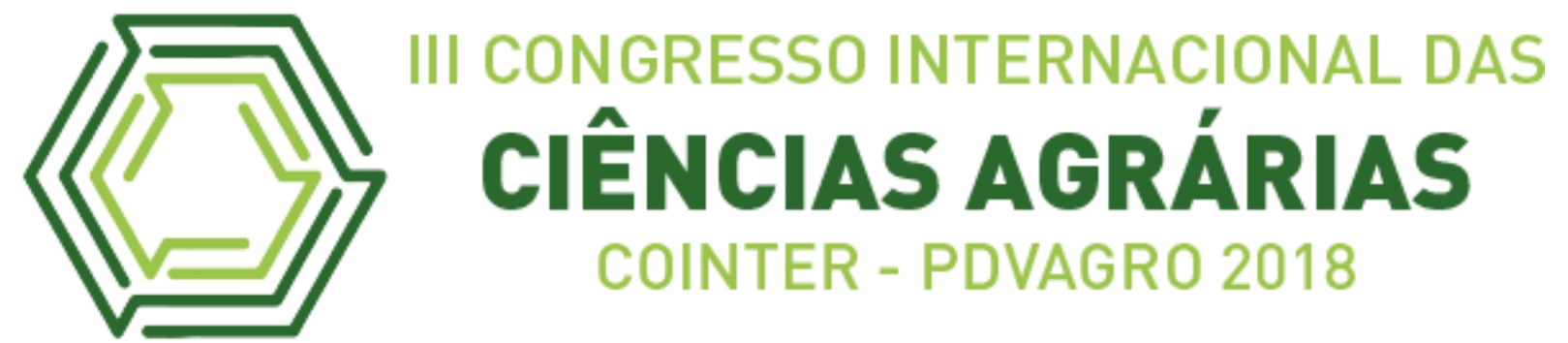

\title{
CARACTERÍSTICAS QUALITATIVAS DA CARCAÇA DE CORDEIROS CONFINADOS ALIMENTADOS COM FONTES PROTEICAS ALTERNATIVAS
}

\section{QUALITATIVE CHARACTERISTICS OF THE CARCASS OF LAMBS CONFINED WITH ALTERNATIVE PROTEIN SOURCES}

\author{
Apresentação: Pôster
}

Brenda Adelino de Macêdo Campelo; Joederson Luiz Santos Dantas 2; Antonio Leandro Chaves Gurgel ${ }^{3}$; Gelson dos Santos Difante ${ }^{4}$; Marcone Geraldo Costa ${ }^{5}$

\section{DOI: https://doi.org/10.31692/2526-7701.IIICOINTERPDVAGRO.2018.00353}

\section{Introdução}

A criação de ovinos tem grande importância econômica e social para região Nordeste. Contudo, nos sistemas de produção de ovinos o farelo de soja é o concentrado proteico mais utilizado, porém seu alto custo restringe o seu uso em regiões distantes daquelas produtoras de grãos, o que justifica a busca constante por alimentos que venham substituir em parte o farelo de soja (GURGEL et al., 2018). Desta forma torna-se necessária a busca por alternativas alimentares na tentativa de diminuir custo, sem prejudicar a qualidade da carcaça, aumentando assim, a rentabilidade do sistema. A utilização de forrageiras adaptadas à região Nordeste, como palma forrageira e o feno de capim-massai, bem como, o uso de fontes proteicas alternativas que não concorram diretamente com a alimentação humana, e que possam apresentar uma boa relação custo/benefício, pode ser uma alternativa para produção de ovinos de corte.

Assim, a utilização de fontes proteicas alternativas como a torta de coco, torta de babaçu e de algodão em substituição ao farelo de soja pode ser uma alternativa importante para reduzir os custos com a nutrição, diminuir o período de terminação e melhorar as características do produto final. Com isso, objetivou-se avaliar as características qualitativas da carcaça de cordeiros confinados alimentados com fontes proteicas.

\footnotetext{
${ }^{1}$ Engenharia Agronômica, Universidade Federal do Rio Grande do Norte- UFRN, brendadelino@gmail.com

2 Zootecnista, Mestre em Produção Animal - UFRN joedersondantas@outlook.com

${ }^{3}$ Mestrando, Programa de Pós-graduação em Produção Animal, UAECA - UFRN, antonioleandro09@gmail.com

${ }^{4}$ Bolsista PQ do CNPq, Programa de Pós-graduação em Ciência Animal/FAMEZ/UFMS, gdifante@hotmail.com

${ }^{5}$ Doutor Professor do Programa de Pós-Graduação em Produção Animal, UAECA - UFRN, marconegc@ufrnet.br
} 


\section{Fundamentação Teórica}

O confinamento de ovinos tem recebido nos últimos anos crescente adoção em virtude da redução do tempo para o abate, da maior eficiência no controle sanitário, da melhor qualidade da carcaça, da manutenção da oferta de forragem no período de escassez e, consequentemente, de maior regularidade na produção e na qualidade da carne ovina disponibilizada no mercado (LAGE et al., 2010). Associada a esta técnica de terminação o uso de coprodutos tem sido avaliados como alternativa aos alimentos convencionais, como o farelo de soja, por seu alto custo, torna pouco rentável os programas de terminação dos animais confinados.

Nesse contexto, subprodutos da indústria do biodiesel e da agroindústria podem ser fontes proteicas promissoras para diminuir os custos de produção em sistemas intensivos e semi-intensivos de criação, já que existe a necessidade da destinação dos subprodutos gerados pelas indústrias com a finalidade de prevenir danos ao meio ambiente.

No processo de produção de carne ovina, a obtenção de carcaças com deposição adequada de gordura e carne mais tenra são aspectos interessantes para os consumidores, que exigem qualidade dos produtos (FRESCURA et al., 2005). De acordo com Bueno et al. (2000), a padronização das carcaças de cordeiros é necessária para valorizar o produto e atrair consumidores.

Além da padronização, outras medidas auxiliares, como a área de olho de lombo (AOL) e a espessura de gordura de cobertura (EGC) na secção do músculo Longissimus dorsi a partir de imagens tomadas entre a $12^{\mathrm{a}}$ e $13^{\mathrm{a}}$ costelas são importantes, uma vez que, obtidas por técnicos experientes, têm apresentado alta repetibilidade, assim como altas correlações com as medidas correspondentes tomadas na carcaça após o abate (Moser et al., 1998; Hassen et al., 1999).

\section{Metodologia}

O experimento foi conduzido na Unidade Acadêmica Especializada em Ciências Agrárias (UAECIA), localizada na Escola Agrícola de Jundiaí, Campus de Macaíba da Universidade Federal do Rio Grande do Norte - UFRN, em Macaíba RN, na área experimental do Grupo de Estudos em Forragicultura (GEFOR) da UFRN. Todas as práticas 
de manejo animal seguiram as recomendações do Conselho Nacional de Controle da Experimentação Animal (CONCEA).

Foram utilizados 32 cordeiros SPRD (sem padrão racial definido) inteiros, oriundos do rebanho do GEFOR, com peso vivo médio inicial de 22,34 $\pm 2,05 \mathrm{~kg}$ e idade média de 4 meses. Os animais foram distribuídos em delineamento inteiramente casualizado e passaram por um período de 15 dias de adaptação às instalações e manejo. O período experimental foi de 08/08/2016 a 13/12/2016. Os tratamentos experimentais consistiram na associação da palma forrageira e feno de capim massai (Panicum maximum cv. Massai) a diferentes fontes proteicas, sendo eles: farelo de soja, torta de babaçu, torta de coco, torta de algodão.

Ao atingirem peso aproximado de $35 \mathrm{~kg}$ os animais foram submetidos a jejum de sólidos e dieta hídrica de 16 horas para serem abatidos. Após o abate, esfola e evisceração as carcaças foram transferidas para câmara frigorífica a $4^{\circ} \mathrm{C}$, onde foi mantida por 24 horas, após esse período as carcaças foram seccionadas ao meio, e na meia-carcaça esquerda, realizou-se um corte transversal entre a $12^{\mathrm{a}}$ e $13^{\mathrm{a}}$ costelas, para medição da área de olho-de-lombo (AOL) do músculo Longissimus dorsi, pelo traçado do contorno do músculo em folha plástica de transparência, para posterior determinação da área com o auxílio de um planímetro digital (HAFF®, modelo Digiplan). Também no músculo Longissimus dorsi, entre a última vértebra torácica e primeira lombar, com auxílio de um paquímetro digital determinadas as medidas $\mathrm{C}$ (espessura mínima de gordura de cobertura) e a medida GR (espessura máxima de gordura).

O delineamento foi inteiramente ao acaso, com quatro tratamentos e oito repetições. Os dados foram submetidos à análise variância e quando significativos pelo teste $\mathrm{F}$, o efeito das fontes proteicas analisadas pelo teste de Tukey a 5\% de significância.

\section{Resultados e Discussões}

Não houve efeito $(\mathrm{P}>0,05)$ das fontes proteicas para espessura mínima $(2,29 \mathrm{~mm}) \mathrm{e}$ máxima $(6,51 \mathrm{~mm})$ de cobertura (Tabela 1). A composição tecidual da carcaça está diretamente relacionada com a qualidade dos cortes cárneos, e na quantidade de tecido muscular, adiposo e ósseo, fatores determinantes no rendimento e na composição química da carcaça.

A semelhança dos pesos vivos de abate, possivelmente afetou na falta de diferença na espessura de gordura, pelo fato do abate ocorrer quando os animais atingissem peso médio fixado em $35 \mathrm{~kg}$. 
Tabela 1. Características qualitativas da carcaça de cordeiros confinados alimentado com fontes proteicas alternativas

\begin{tabular}{|c|c|c|c|c|c|c|}
\hline \multirow{2}{*}{ Variáveis } & \multicolumn{4}{|c|}{ Tratamentos } & \multirow{2}{*}{ EPM } & \multirow{2}{*}{ Valor P } \\
\hline & Soja & Babaçu & Coco & Algodão & & \\
\hline Espessura mínima de gordura (mm) & 2,84 & 2,36 & 1,85 & 2,10 & 0,446 & 0,4469 \\
\hline Espessura máxima de gordura (mm) & 6,36 & 7,22 & 6,67 & 5,80 & 1,422 & 0,9122 \\
\hline Área de olho de lombo $\left(\mathrm{cm}^{2}\right)$ & $15,11^{\mathrm{a}}$ & $14,2^{\mathrm{ab}}$ & $13,65^{\mathrm{b}}$ & $14,62^{\mathrm{ab}}$ & 0,308 & 0,0161 \\
\hline
\end{tabular}

A área de olho de lombo tem sido diretamente ligada ao teor de músculo na carcaça, considerada medida objetiva de grande valor na predição, pois quanto maior a AOL, mais valorizada será a carcaça (Bueno et al. 2000). Não houve influência $(\mathrm{P}>0,05)$ para AOL dos animais alimentados com farelo de soja, torta de babaçu ou torta de algodão. Foi observado menor $(\mathrm{P}<0,05)$ valor de AOL nos animais que receberam torta de coco em relação aos que receberam farelo de soja, porém não diferiu dos que receberam torta de babaçu ou torta de algodão.

Medeiros (2014), trabalhando com cordeiros SPRD x 1/2 Soinga alimentados com palma forrageira e diferentes fontes de feno de leguminosas, observou valores médios de $10,34 \mathrm{~cm}^{2}$ de AOL dos animais que foram abatidos com peso médio de 33,28kg. Assim, os animais que receberam torta de coco, mesmo apresentando valores mais baixos para AOL em comparação aos animais que receberam farelo de soja, apresentam valores mais elevados em relação aos animais estudados por Medeiros (2014), o que nos leva a inferir que outros parâmetros devem ser avaliados para validar ou não a viabilidade fonte alternativa.

Tal comportamento pode estar relacionado ao GMD dos animais, uma vez que no trabalho de desempenho foi observado que os animais que receberam torta de coco apresentaram menor GMD (144,31g/dia) e que os que receberam farelo de soja (196,38g/dia), e por sua vez, tal resultado provavelmente foi influenciado pelos consumos de matéria seca (MS) e Nutrientes Digestíveis Totais (NDT), onde os animais que receberam farelo de soja consumiram em média 1,27 kgMS/dia e 0,99kgNDT/dia, e os que receberam a torta de coco consumiram em média 0,77 kgMS/dia e 0,71kgNDT/dia, respectivamente (Dantas, 2018).

\section{Conclusões}


As fontes proteicas alternativas tortas de babaçu e de algodão podem ser utilizadas como fontes alternativas ao farelo de soja em dietas para acabamento de ovinos de corte em confinamento quando algumas características qualitativas de carcaça são levadas em consideração. No entanto, outros parâmetros devem ser considerados na tomada final de decisão.

\section{Referências}

BOSA, R.; FATURI, C.; VASCONCELOS, H. G. R., et al. Consumo e digestibilidade aparente de dietas com diferentes níveis de inclusões de torta de coco para alimentação de ovinos. Acta Scientiarum. Animal Sciences. Maringá, v. 34, n. 1, p. 57-62, Jan-Mar., 2012.

BUENO, S.M.; CUNHA, E.A.; SANTOS, L.E. et al. Características de carcaça de cordeiros Suffolk abatidos em diferentes idades. Revista Brasileira de Zootecnia, v.29, n.6, p.1803$1810,2000$.

CARTAXO, F. Q.; SOUSA, W. H. Correlações entre as características obtidas in vivo por ultra-som e as obtidas na carcaça de cordeiros terminados em confinamento. Revista Brasileira de Zootecnia, v. 37, n. 8, p. 1490-1495, 2008.

DANTAS, J.L.S. Fontes proteicas alternativas na alimentação de ovinos em confinamento. Macaíba, 2018. 44p. Dissertação. Programa de Pós-Graduação em Produção Animal, UAECA-UFRN, 2018.

FRESCURA, R.B.M.; PIRES, C.C.; SILVA, J.H.S. et al. Avaliação das proporções dos cortes da carcaça, características da carne e avaliação dos componentes do peso vivo de cordeiros. Revista Brasileira de Zootecnia, v.34, n.1, p.167-174, 2005.

GURGEL, A.L.C.; DIFANTE, G.S.; ROBERTO, F.F.S.; DANTAS, J.L.S. Suplementação estratégica para animais em pasto. PUBVET, v.12, n.4, a62, p.1-10, 2018.

LAGE, J.F.; RODRIGUES, P.V.; PEREIRA, L.G.R. et al. Glicerina bruta na dieta de cordeiros terminados em confinamento. Pesquisa Agropecuária Brasileira, v.45, p.10121020, 2010.

MEDEIROS, M.C. Característica da carcaça de ovinos confinados alimentados com palma forrageira e feno de leguminosas. Macaíba-RN, 2014. 64p. Dissertação. Programa de PósGraduação em Produção Animal, UAECA-UFRN, 2014. 